\title{
Anonymous birth: Biographical knowledge and dyadic coping in adoptive mothers and fathers
}

\author{
Anna Felnhofer ${ }^{1,2}$ (D) Jennifer Kernreiter ${ }^{1,2,3}$ (D) $\cdot$ Claudia Klier $^{1,2}$ (D) $\cdot$ Mercedes M. Huscsava $^{2,4}$ (D) Christian Fiala $^{3}$ (D) \\ Michael Zeiler ${ }^{2,4}$ iD
}

Accepted: 10 March 2021 / Published online: 20 March 2021

(C) The Author(s) 2021

\begin{abstract}
Research on adoptive parents of anonymously born children is still scarce. Open issues are (1) examining how much biographical information is available to adoptive parents, (2) considering differences between adoptive mothers and fathers, and (3) understanding what affects their dyadic coping. Hence, this study set out to compare adoptive mothers' and fathers' mental health, attachment styles, dyadic coping, and biographical knowledge, and to identify predictors of dyadic coping. 62 mothers and 40 fathers (mean age: 46 years) raising an anonymously born adoptee answered online or paper-pencil versions of the Brief Symptom Inventory, Vulnerable Attachment Style Questionnaire, Dyadic Coping Inventory, Child Behavior Checklist, and a checklist of biographical data. Descriptive analyses showed that biographical knowledge was generally low in adoptive parents. More information was available on the birth mother than the birth father, with letters being the most common memorial. Furthermore, student t-tests revealed few differences: adoptive mothers reported to be more anxious and rated their ability to communicate stress and common dyadic coping as higher than did adoptive fathers. Finally, a hierarchical linear regression identified knowledge of more biographical data, parents' older age as well as child's younger age and higher psychopathology scores as predictors of better adoptive parents' dyadic coping. These findings highlight the difficult task of gathering biographical information whilst maintaining the birth mother's anonymity. They also stress the need of further research which may inform policies tailored to the specific needs of adoptive parents in the context of anonymous birth.
\end{abstract}

Keywords Anonymously adopted children and adolescent $\cdot$ Adoptees $\cdot$ Adoptive parents $\cdot$ Gender

\section{Introduction}

Adopting a child is considered a major event in a couples' life (Bird et al., 2002). In contrast to biological parents, adoptive parents are faced with challenges which are specific to the context of adoption and may exacerbate the demands of parenthood, as well as impede adjustment to the parental role (Calvo et al., 2015; Canzi et al., 2019b). In particular, stress

Michael Zeiler

michael.zeiler@meduniwien.ac.at

1 Department of Pediatrics and Adolescent Medicine, Medical University of Vienna, Vienna, Austria

2 Comprehensive Center for Pediatrics, Medical University of Vienna, Vienna, Austria

3 Gynmed Clinic Vienna, Mariahilfer Guertel 37, 1150 Vienna, Austria

4 Department of Child and Adolescent Psychiatry, Medical University of Vienna, Waehringer Guertel 18-20, 1090 Vienna, Austria may stem from prior experiences of infertility (Daniluk \& Hurtig-Mitchell, 2003), from the adoptee's possible history of early life adversities (e.g. Smith et al., 2018), the child's older age at adoption (e.g. Bird et al., 2002; Canzi et al., 2019c), prevailing developmental delays (Viana \& Welsh, 2010), medical problems (e.g. Judge, 2003), and emotional and/or behavioral difficulties (e.g. Canzi et al., 2019c).

Additional strain may come from the fact that in some cases of adoption, determining the adoptee's history is difficult (Bird et al., 2002), and contact with birth families is impossible. Particularly, in the context of safe relinquishment (Orliss et al., 2019) or anonymous birth (Grylli et al., 2016) which allow the safe abandonment of infants without legal prosecution, biographical data is often unknown. Limited biographical knowledge and lack of birth family contact, however, are thought to bear unique challenges not only for the anonymously born child, but also for adoptive parents (e.g. Orliss et al., 2019). While some research exists on semi-open international adoptions (e.g. Hails et al., 2019), studies on closed adoption forms like anonymous birth are still scarce. 
Furthermore, there is a pending need to include the unique perspective of adoptive fathers to better understand an adoptive couple's functioning and coping with the stress of parenting (Grotevant et al., 2019).

Hence, the current paper introduces a cross-sectional study on adoptive mothers and fathers of anonymously born children. Following a comprehensive overview of the existing literature, the focus is put on examining adoptive parents' biographical knowledge of the adoptee's birth parents and on evaluating possible differences between adoptive mothers and fathers regarding their mental health, attachment styles and dyadic coping. Additionally, possible predictors of adoptive parents' dyadic coping are analyzed.

\section{Biographical Knowledge in Anonymous Adoption}

Currently, there is consensus that knowing about their birth families and maintaining some form of contact with them is beneficial to the adopted child (Von Korff \& Grotevant, 2011). Biographical knowledge and contact are thought to promote not only an adoptive identity formation (Farr et al., 2018) and more positive family communication, but also to reduce the risk of externalizing problems (Grotevant et al., 2019). However, this type of openness is not always possible: Apart from international adoptions, where the availability of facts about the birth family may be limited (see Bird et al., 2002; Roberson, 2006; Smith et al., 2018), safe surrender programs like anonymous birth typically go along with even less background information and no birth family contact at all (see Orliss et al., 2019).

These programs allow for placing the newborn in a baby hatch or for anonymously delivering the child in a hospital without risking legal penalty (Grylli et al., 2016; Orliss et al., 2019). In contrast to baby hatches, where no information is typically conveyed, anonymously delivering the child in a hospital offers the opportunity to (at least) record medical facts related to the birth process. Also, the birth mother is encouraged by hospital and juvenile custody service staff to leave information about herself (e.g. in the form of a letter or photograph, Grylli et al., 2016). However, anecdotal evidence shows that biographical information left by the birth mother/ the birth parents is limited, and establishment of contact with the birth family is impossible (see Galliez et al., 2019).

Overall, there is a lack of data on safely surrendered children (Orliss et al., 2019), and even less is known about the impact of the type and extent of biographical knowledge on adoptive parents of anonymously born children. Studies on more open forms of adoption (international or domestic) provide some indication about the nature of this association: while they generally show that attitudes towards openness be it biographical knowledge or communicative openness (Henze-Pedersen, 2019) - vary greatly across adoptive families (Grotevant et al., 2019), research has also found adoptive mothers to report more negative or ambiguous feelings about birth mother contact than adoptive fathers (Farr et al., 2018). Consequently, further studies are needed to establish what and how much adoptive parents know about the biographies of their anonymously born children, and to determine whether this knowledge is associated with better parental coping.

\section{Differences between Adoptive Mothers and Adoptive Fathers}

Adoptive couples are faced with the task of promoting adequate adjustment and secure attachment of the adopted child, as well as to support the in understanding their adoptive identity (Hock \& Mooradian, 2012; Roberson, 2006). Typically, adoptive mothers and fathers are both strongly engaged in these tasks (Canzi et al., 2019a), and past research emphasizes the specific contribution each parent makes to the child's upbringing and welfare: For instance, it has been shown that parents perceive the child's temperament and mental health differently (Felnhofer et al., 2019, 2020; Phares et al., 2005). Accordingly, it has been assumed that mothers and fathers may also perceive and handle parenting stress in a different manner. While some studies (e.g. Rosnati et al., 2013) support this, others (e.g. Ponnet et al., 2013) have failed to find a difference, leaving it an open issue in this research domain.

In the context of adoption, adoptive fathers seem to constitute a particular resource for the child's adjustment and development (Canzi et al., 2019a; Ferrari et al., 2015). Yet, most adoption studies focus only on adoptive mothers (Canzi et al., $2019 b$ ), strongly highlighting the necessity of considering both. It is expected that examining adoptive mothers and adoptive fathers separately, and comparing each of their perspectives will shed more light on the nature of how parents cope with the unique task of adopting an anonymously born child.

\section{Adoptive Parents' Dyadic Coping}

One crucial factor helping couples to deal with the demands of parenting - independent of whether they are the biological or adoptive parents -, is successful dyadic coping. Guided by the Systemic Transactional Model (STM, Bodenmann, 1995), an extension of Lazarus' and Folkman's (1984) individualoriented stress model (Meuwly et al., 2012), dyadic coping describes a couple's ability to manage stress both on an individual as well as on a dyadic level (i.e. joint appraisal of, and response to stressors, Bodenmann et al., 2006). As such, it considers the interdependence of handling stress as a couple (Alves et al., 2020) and hence allows for a more in-depth analysis of relationship functioning. In the Process Model of Parenting (Belsky, 1984), stress is assumed to negatively impact parenting behaviors, with negative consequences not only for the parents' own well-being, but also for the child's 
welfare (Bodenmann, 2008; Zemp et al., 2016). In the past, successful dyadic coping has been found to improve relationship satisfaction, marital quality (Falconier et al., 2015; Hilpert et al., 2016), dyadic adjustment and quality of life (Alves et al., 2020).

While a reasonable amount of data on adoptive parents' biographical knowledge of birth parents are available, dyadic coping in adoptive parents remains an understudied subject. To our knowledge, so far only two studies have examined dyadic coping in the context of adoption. Hock and Mooradian (2012) found that positive dyadic coping was linked to better co-parenting. Yet, this association was tested only in adoptive mothers, leaving open questions with regard to adoptive fathers. Canzi et al. (2019a), in turn, only interviewed prospective adoptive parents. Hence, their results are likely not comparable to those parents who are already in the midst of bringing up an adoptee. Furthermore, both studies only focus on a specific aspect of dyadic coping, not taking into account the range of factors which may possibly impact it (see Berg \& Upchurch, 2007), such as contextual issues (e.g., socioeconomic status, biographical knowledge) and developmental factors (e.g., length of adoption).

Additionally, past studies (e.g. Canzi et al., 2019c) indicate that children's age at adoption and existing emotional and behavioral difficulties predict both adoptive mothers' and adoptive fathers' stress levels. Similarly, parental mental health has been discussed to significantly impact relationship quality and coping with stress (Viana $\&$ Welsh, 2010). Although a plethora of studies exists on birth parents' mental health and adjustment to parenthood, only few have examined these issues in adoptive parents (Anthony et al., 2019). Among these, one has found that adoptive parents with high depression levels prior to adoption later tend to exhibit more parenting stress (Goldberg \& Smith, 2014). Finally, attachment style (Bowlby, 1973) may also impact parenting. Past research (Meuwly et al., 2012) suggests that those who perceive and receive more positive coping from their partner, recover faster from stress, and that this association is moderated by attachment style and gender: Hence, women with high attachment anxiety were less likely to benefit from dyadic coping regarding stress recovery. Generally, parents' own attachment experiences are thought to shape their behavior towards their child, with insecurely attached parents (i.e. dismissive, or ambivalent) exhibiting more difficulties in adequately responding to the children's needs (Caltabiano \& Thorpe, 2007). Past adoption research has indeed found that successful caregiving may be dependent on the adoptive mother's secure attachment style (Kaniuk et al., 2004), yet, the scarcity of research on this subject - especially concerning adoptive fathers precludes definite conclusions.

\section{Objective}

Raising an anonymously born child presents a unique challenge for adoptive parents. Due to the anonymity of safe relinquishment, background information is usually scarce, and contact with the birth family is not possible. While data for more open forms of adoption are available, research on safely surrendered children is insufficient (Orliss et al., 2019). Also, there is a pending need to expand the focus by including adoptive fathers when researching adoptive couples. Hence, this study set out to evaluate the extent of biographical knowledge in adoptive parents of anonymously born children. Furthermore, key factors of parental well-being were compared between adoptive mothers and fathers. Finally, possible predictors of dyadic coping were analyzed.

\section{Methods}

\section{Procedure and Participants}

This is a cross sectional study on mothers and fathers who had anonymously adopted a child. Participants were recruited via three private adoption services and six public adoption offices at the Austrian juvenile custody service, as well as via eight resident pediatricians in Vienna. Adoptive mothers and fathers with sufficient German language skills were eligible for participation. Written informed consent was obtained from adoptive parents prior to their participation. Both adoptive parents were invited to participate in this study; however, data were also included if only one parent took part. Upon agreeing to take part in the study, participants were free to choose whether they preferred to complete a paper-pencil, or an online version of the survey. If they preferred the paper-pencil questionnaires, they were sent via postal mail, including an addressed return envelope and the instruction not to include any personalized information (i.e., address) to ensure anonymization. For the online version, a link was provided which led to an online survey programmed via the open-source platform SoSci Survey (www.soscisurvey.de). Data were collected anonymously, and no sensitive information (i.e. IP-address) was stored. Participants did not receive any remuneration, and ethical approval was granted by the local institutional review board (\#1354/2013).

\section{Measures}

The following demographic variables on the parents themselves, as well as on the adoptive child such as gender, current age, age at adoption, time since adoption, highest educational degree, marital status, years in relationship prior to adoption etc. were collected. In addition, participants completed the following questionnaires: 
Biographical Knowledge Regarding Birth Circumstances and Biological Parents A questionnaire containing 40 checkboxes was constructed on the basis of past research (e.g., Wrobel \& Grotevant, 2019) to assess whether adoptive parents had received any personal biographical information on the biological parents (i.e. age, country of origin, education, marital status, genetic diseases) or on the circumstances of the birth (i.e. birth date, place of birth, birth weight, type of delivery). Furthermore, adoptive parents were asked whether they had obtained any 'memorials' (i.e. photos, letters, statements for the abandoned child).

Parental Mental Health The Brief Symptom Inventory (BSI, Franke, 2000) was used to assess different aspects of parental psychopathology. This questionnaire consists of 53 items which are rated on a 5 -point Likert scale $(0=$ not at all, $4=$ very strongly). Item ratings are summed up to a total score representing global psychopathology, and nine subscales representing specific mental health (somatization, obsessivecompulsive, interpersonal sensitivity, depression, anxiety, hostility, phobic anxiety, paranoid ideation, psychoticism). Higher values indicate higher levels of psychopathology. The internal consistency is excellent for the total score $(\alpha=.92)$ and low to acceptable $(\alpha>.60)$ for most subscales (see also Franke, 2000). Clinically relevant psychopathology scores were derived using gender and age specific T-scores, with $\mathrm{T}$-scores $\geq 60$ indicating clinically relevant mental health problems.

Attachment Style The Vulnerable Attachment Style Questionnaire (VASQ, Bifulco et al., 2003) assesses behaviors, emotions and attitudes related to attachment relationship styles using 22 items (rated on a 5-point Likert scale, $1=$ strongly disagree, $5=$ strongly agree) and results in two factors: the first factor ('insecurity') represents feelings and attitudes relating to discomfort with closeness to others (e.g. inability to trust, fear of being let down); the second factor ('proximity seeking') comprises other-dependence or approach behavior (e.g. relying on others to make decisions, being anxious when close people are away). Furthermore, items are aggregated to a total score with higher values indicating higher levels of vulnerable attachment. The internal consistency for this study was $\alpha=.82$ (insecurity) and $\alpha=.67$ (proximity seeking). The authors have proposed cutoff values of 30 for the insecurity subscale and 27 for the proximity-seeking subscale to define highly vulnerable attachment.

Dyadic Coping The Dyadic Coping Inventory (DCI, Bodenmann, 2008) was designed to measure perceived communication with the partner and dyadic coping in situations when one or both partners are stressed. This self-report questionnaire comprises 35 items which are rated on a 5-point
Likert scale $(1=$ very rarely, $5=$ very often $)$ and are summed up to ten subscores and a total score. Two subscales describe to which degree stress is communicated by oneself and by the partner. Two subscales assess supportive dyadic coping, which means that one partner provides problem- or emotionfocused support if needed. Two subscales assess the degree of delegated dyadic coping, which means that one partner takes over responsibilities to reduce the partner's stress. Two subscales reflect the degree of negative dyadic coping (by oneself and the partner), which includes hostile, ambivalent, or superficial actions or words. Another subscale measures common dyadic coping, which means that both partners work together to handle stressful situations. The last subscale ('evaluation of dyadic coping') represents the satisfaction of the support one partner receives from the other partner. In addition to the subscales, a total score is computed. Coping levels are regarded average if this total score is above the cut-off of 111 (see Bodenmann et al., 2018). In this study, the internal consistency was $\alpha=.91$ for the total score and ranged between .61 and .86 for the subscales.

Adoptive Child's Mental Health The Child Behavior Checklist (CBCL, 2 versions: < 4 years, Achenbach \& Rescorla, 2000; $\geq$ 4 years, Achenbach, 1991) was used to assess adoptive mothers' and fathers' perceptions of their adoptive child's mental health. This questionnaire encompasses a wide range of internalizing and externalizing behavioral problems (101 items in the version for younger children, 112 items in the version for older children) which are rated on a 3-point scale $(0=$ not true, $1=$ somewhat or sometimes true, $2=$ very true or very often true). For the purpose of this study, only the total problem score (sum of all items), representing the overall psychological burden, was used. Cronbach's alpha of the total score was .96 (version for children $<4$ years) and .88 (version for children, $\geq 4$ years), respectively. We used T-scores based on gender and age specific norms, which allows for merging scores from the two CBCL versions. Higher scores indicate higher levels of adoptive children's mental health problems. We additionally calculated z-scores to compare evaluations of adoptive mother and fathers.

\section{Results}

Data were analyzed using IBM SPSS Statistics 26 (SPSS, Inc. Chicago, USA). A significance level of $p<0.05$ was used for all analyses. We calculated descriptive statistics (means, standard deviations, percentages) to describe the study population and biographical knowledge on biological parents (separately for adoptive parents' gender). We used Student t-tests (for continuous variables, including effect sizes in terms of Cohen's d) and $\chi^{2}$-tests (for categorical variables) to analyze differences between outcome variables obtained from 
adoptive mothers and fathers. Furthermore, a hierarchical linear regression was performed to identify possible predictors of parental dyadic coping.

\section{Sample}

The participants' flow is shown in Fig. 1. Of 169 datasets received, 67 had to be excluded due to incomplete data $(n=$ 51). To ensure homogeneity of the sample and thus, comparison of the data, reports from adoptive parents whose adoptive child had been placed in a baby hatch $(n=16)$ were excluded from the analysis. Finally, data from 62 adoptive mothers and 40 adoptive fathers of anonymously adopted children $(n=$ $102 ; 86.3 \%$ online questionnaire, $13.7 \%$ paper-pencil form) were included in the analysis. The age ranged between 34 and 77 years for mothers $(M=45.35, S D=6.30)$ and between 33 and 62 years for fathers $(\mathrm{M}=46.45, \mathrm{SD}=6.52)$. Overall, $55.7 \%$ of adoptive mothers and $57.5 \%$ of adoptive fathers had a university degree, the majority of participants were married, or lived in partnership, and $56.5 \%$ of adoptive mothers and $62.5 \%$ of adoptive fathers lived in an urban area (see Table 1). There were no significant differences between adoptive mothers and adoptive fathers with regard to key demographic variables, only the percentage of participants with full-time employment was significantly higher in adoptive fathers $(85.0 \%)$ compared to mothers $(17.7 \%)$. The parents' age when adopting the child was 38 years (mothers), respectively 37 years (fathers) on average. The average time since adopting the child was 6.82 years $(\mathrm{SD}=3.27)$ in adoptive mothers and 7.42 years $(\mathrm{SD}=4.02)$ in adoptive fathers. Adoptive children's overall age ranged between 2 and 17 years $(\mathrm{M}=6.04, \mathrm{SD}=3.52)$. Their mental health problems were rated within the norm of the general population of children (T-score $\mathrm{M}=50.28, \mathrm{SD}=12.18$ ) with no differences emerging between adoptive mothers' and fathers' evaluations (zscores: mother: $\mathrm{M}=0.01$ ( $\mathrm{SD}=0.95)$, father: $\mathrm{M}=-0.02$ $(\mathrm{SD}=1.08) ; t(100)=0.136, p=.892, \mathrm{~d}=0.03)$.

\section{Biographical Knowledge Regarding Birth Circumstances and Biological Parents}

The biographical knowledge regarding birth circumstances, or the biological parents was generally low among adoptive parents (see Table 2). Of the 40 factors assessed, on average, adoptive mothers reported to know only of $\mathrm{M}=10.42$ ( $\mathrm{SD}=$ 4.91) factors, while fathers knew of $\mathrm{M}=10.00(\mathrm{SD}=4.35)$ factors $(t(100)=0.440 ; p=.661, \mathrm{~d}=0.09)$. On average, $93.5 \%$ of adoptive mothers and $95.0 \%$ of fathers were able to name at least some background information on birth circumstances, with no difference between parents. While the knowledge of any personal information on the biological mother was reported by $72.6 \%$ of adoptive mothers and $77.5 \%$ of adoptive fathers, personal information on the biological father was scarce among adoptive parents (mothers: $17.7 \%$, fathers: $22.5 \%$ ). Memorials of the biological mother (such as photos, letters) were available to $69.4 \%$ of adoptive mothers and to $60.0 \%$ of adoptive fathers, with letters being by far the most commonly relayed memorial. Memorials of the biological father, in turn, were rarely available $(1.6 \%$ and $5.0 \%)$.

\section{Differences between Adoptive Mothers and Fathers}

As assessed by the BSI total score, there was no significant difference $(t(97)=0.767, p=.445, \mathrm{~d}=0.16)$ between adoptive mothers' $(\mathrm{M}=7.20, \mathrm{SD}=7.30)$ and fathers' $(\mathrm{M}=6.05, \mathrm{SD}=$ 8.26) psychopathology. When considering the subscales, higher levels of anxiety were observed in adoptive mothers as compared to adoptive fathers $(t(100)=2.330, p=.022, \mathrm{~d}=$ 0.48 ), all other subscales were non-significant. With regard to dyadic coping, adoptive mothers and fathers showed similar total DCI scores $(t(96)=1.328, p=.187, \mathrm{~d}=0.27)$. Yet, significantly higher levels of stress communicated by oneself $(t(97)=3.273, p<.001, \mathrm{~d}=0.67)$ and common dyadic coping $(t(97)=2.225, p=.028, \mathrm{~d}=0.46)$ were reported by adoptive mothers as compared to adoptive fathers. No significant parental differences were observed for the total VASQ score, or any of the subscales. See Table 3 for more details.

Additionally, we compared all total scores to the according clinical cut-offs to assess whether adoptive parents fell into the clinical problem score range. Regarding parental psychopathology, $3.3 \%$ of adoptive mothers $2.6 \%$ of adoptive fathers showed clinically relevant scores $\left(\chi^{2}(1)=0.048, p=.827\right)$. Regarding dyadic coping, below average scores were observed in $18.6 \%$ of adoptive mothers and $20.5 \%$ of adoptive fathers $\left(\chi^{2}(1)=0.052, p=.819\right)$. Vulnerable attachment in terms of insecurity was found in $15.3 \%$ of adoptive mothers and $10.3 \%$ of adoptive fathers $\left(\chi^{2}(1)=0.510, p=.475\right)$, while vulnerable proximity seeking scores were observed in $40.7 \%$ of adoptive mothers and $38.5 \%$ of adoptive fathers $\left(\chi^{2}(1)=\right.$ $0.048, p=.826)$.

\section{Predictors of Dyadic Coping}

Finally, we performed hierarchical linear regression models to analyze whether the total number of known background factors, the adoptive child's psychopathology, parental psychopathology and parental attachment style predicted parental dyadic coping when controlling for adoptive parents' and child's gender and age, as well as time since adoption. Model fit parameters and regression coefficients of the final models are shown in Table 4. A higher number of known background factors was significantly associated with better dyadic coping ( $\beta=.251, p=.013)$ when controlling for parent's and child's gender and age, and time since adoption. Furthermore, higher levels of a child's psychopathology was 
Fig. 1 Participants' flow

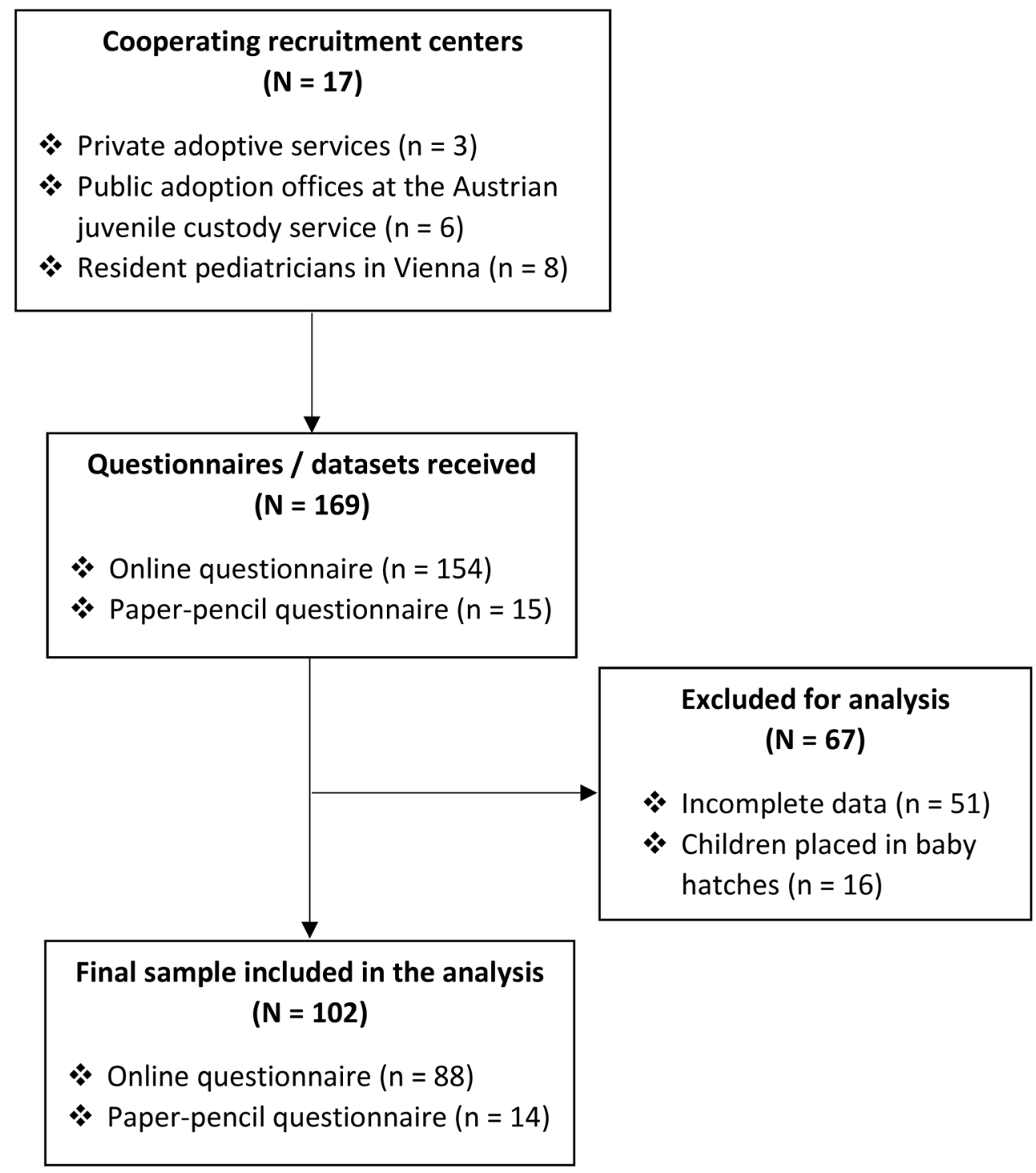

significantly associated with worse dyadic coping $(\beta=-334$, $p=.002$ ). There was a tendency for a similar relationship between parental psychopathology and dyadic coping, but this association did not reach statistical significance $(p=.067)$. Moreover, the adoptive parents' and the adoptee's age significantly predicted dyadic coping. The parents' gender was not significantly associated with dyadic coping when controlling for the other predictors in the model. All sets of predictors in the model explained $34.6 \%$ of the variance in dyadic coping.

\section{Discussion}

Given the insufficient data on anonymously born children, and in view of the particularities surrounding this type of adoption (i.e., limited biographical information), the current study had the goal of exploring the field. The main objectives were to examine how much biographical information is available to adoptive parents, to evaluate differences between adoptive mothers and adoptive fathers, and to better understand what affects their dyadic coping.

\section{Biographical Knowledge}

Generally, biographical knowledge was low in our adoptive parent sample. On average, adoptive mothers and adoptive fathers were able to name only 10 out of 40 biographical factors. Among these, there was more information available on the birth mother than on the birth father. Particularly, demographic data, such as the birth mother's age and education were more accessible to adoptive parents than specifics of the birth mother's personal details (e.g. talents), or medical histories (e.g. genetic diseases). In comparison, no information at all was available on the biological father's health.

The lack of knowledge about the birth parents' health and/ or pre-existing illnesses is particularly relevant, as past studies 
Table 1 Sample characteristics of adoptive mothers, adoptive fathers, and adopted children

\begin{tabular}{|c|c|c|c|c|}
\hline & \multirow{2}{*}{$\begin{array}{l}\text { Adoptive mothers } \\
(N=62)\end{array}$} & \multirow{2}{*}{$\begin{array}{l}\text { Adoptive fathers } \\
(N=40)\end{array}$} & \multicolumn{2}{|l|}{ Group difference } \\
\hline & & & Test statistic (df) & $p$ \\
\hline Age (mean, SD) & $45.35(6.30)$ & $46.45(6.52)$ & $t(98)=0.829$ & .402 \\
\hline \multicolumn{5}{|l|}{ Highest educational degree } \\
\hline University degree $(\mathrm{N}, \%)$ & $34(55.7 \%)$ & $23(57.5 \%)$ & $\chi^{2}(1)=0.031$ & .861 \\
\hline Below university degree $(\mathrm{N}, \%)$ & $27(44.3 \%)$ & $17(42.5 \%)$ & & \\
\hline Missing (N, \%) & 1 & & & \\
\hline \multicolumn{5}{|l|}{ Marital status } \\
\hline Married or living in partnership (N, \%) & $62(100 \%)$ & $39(97.5 \%)$ & $\chi^{2}(1)=1.565$ & .211 \\
\hline Divorced or widowed (N, \%) & $0(0.0 \%)$ & $1(2.5 \%)$ & & \\
\hline Age at adoption (mean, SD) & $38.39(5.50)$ & $36.91(6.89)$ & $t(93)=1.148$ & .254 \\
\hline Years in relationship prior to adoption & $13.46(5.14)$ & $12.56(4.79)$ & $t(88)=0.810$ & .420 \\
\hline Time since adoption in years (mean, SD) & $6.82(3.27)$ & $7.42(4.02)$ & $t(92)=0.788$ & .433 \\
\hline Employment status & & & $\chi^{2}(2)=44.853$ & $<.001$ \\
\hline Full employment (N, \%) & $11(17.7 \%)$ & $34(85.0 \%)$ & & \\
\hline Part-time employment (N, \%) & $41(66.1 \%)$ & $4(10.0 \%)$ & & \\
\hline Other $(\mathrm{N}, \%)$ & $10(16.1 \%)$ & $2(5.0 \%)$ & & \\
\hline Size of residence ${ }^{\mathrm{a}}$ & & & $\chi^{2}(1)=0.367$ & .545 \\
\hline Urban $(\mathrm{N}, \%)$ & $35(56.5 \%)$ & $25(62.5 \%)$ & & \\
\hline Rural (N, \%) & $27(43.5 \%)$ & $15(37.5 \%)$ & & \\
\hline Gender - adoptive child & & & $\chi^{2}(1)=<0.001$ & .987 \\
\hline Female $(\mathrm{N}, \%)$ & $34(54.8 \%)$ & $22(55.0 \%)$ & & \\
\hline Male $(\mathrm{N}, \%)$ & $28(45.2 \%)$ & $18(45.0 \%)$ & & \\
\hline Age - adoptive child (mean, SD) & $5.76(3.38)$ & $6.48(3.73)$ & $t(100)=1.004$ & .318 \\
\hline \multicolumn{5}{|l|}{ CBCL total problems } \\
\hline T-score (mean, SD) & $50.18(12.16)$ & $50.45(12.36)$ & $t(100)=0.110$ & .913 \\
\hline$z$-score (mean, SD) & $0.01(0.95)$ & $-0.02(1.06)$ & $t(100)=0.136$ & .892 \\
\hline
\end{tabular}

Urban: > 10.000 inhabitants, Rural: $\leq 10.000$ inhabitants

$C B C L$, Child Behavior Checklist

have shown that adoptees most frequently seek to learn more about their birth parents' medical and health histories (Wrobel \& Grotevant, 2019). According to the Adoption Curiosity Pathway (ACP, Wrobel \& Dillon, 2009) this need becomes particularly pressing with time, peaking during transition into adulthood (see Skinner-Drawz et al., 2011). Apart from the individual's curiosity to learn more about one's biography, research on international adoption indicates that unknown medical histories are associated with inherent risk factors to the child's development and welfare (Orliss et al., 2019). As such, inaccessible medical records may also pose a stressor to adoptive parents.

Generally, extant literature suggests that adoptive parents seek ways of making biographical information available to their adoptive child, and that they themselves are curious about the child's past (Shaw, 2011). Here, anonymous birth - in contrast to placement in a baby hatch - provides the advantage that the child's birth (e.g. type of delivery) may be documented by hospital staff (Galliez et al., 2019; Grylli et al., 2016). This fact is also reflected in the current findings: The majority of adoptive mothers and fathers reported to possess such information. In addition, anonymously delivering women are encouraged to attend ante-natal care as early as possible (Grylli et al., 2016). This not only ensures adequate medical care, but also allows recording pregnancy related health issues. The present findings suggests that there may be room for improvement in informing and motivating anonymously delivering women to make use of this offer.

In addition to medical histories, finding out more about the birth parents' reason for giving the child up for adoption, or learning about the birth parent's personality and how she or he is doing, may also drive adoptees' and adoptive parents' curiosity (Wrobel \& Dillon, 2009). In our sample, about $70 \%$ of adoptive parents reported to possess a memorial of the biological mothers, the most common form being a letter or a statement of reasons for leaving the child behind. However, only 
Table 2 Biographical knowledge regarding birth circumstances and biological parents

\begin{tabular}{|c|c|c|c|c|}
\hline & \multirow{2}{*}{$\begin{array}{l}\text { Adoptive mothers } \\
(\mathrm{N}=62)\end{array}$} & \multirow{2}{*}{$\begin{array}{l}\text { Adoptive fathers } \\
(\mathrm{N}=40)\end{array}$} & \multicolumn{2}{|l|}{ Group difference } \\
\hline & & & Test statistic (df) & $p$ \\
\hline All background factors (sum) (Mean, SD) & $10.42(4.91)$ & $10.00(4.35)$ & $t(100)=0.440$ & .661 \\
\hline Birth circumstances (sum) (Mean, SD) & $5.76(2.12)$ & $5.50(2.03)$ & $t(100)=0.661$ & .542 \\
\hline Birth circumstances (any) (\%) & $93.5 \%$ & $95.0 \%$ & $\chi^{2}(1)=0.093$ & .761 \\
\hline Place of birth of adoptive child (\%) & $91.9 \%$ & $92.5 \%$ & & \\
\hline Birth date of adoptive child (\%) & $90.3 \%$ & $90.0 \%$ & & \\
\hline Birth weight of adoptive child (\%) & $88.7 \%$ & $85.0 \%$ & & \\
\hline Type of delivery (\%) & $85.5 \%$ & $85.0 \%$ & & \\
\hline Medical newborn screening (\%) & $80.6 \%$ & $72.5 \%$ & & \\
\hline Duration of inpatients stay after delivery $(\%)$ & $58.1 \%$ & $60.0 \%$ & & \\
\hline Place of residence before adoption (\%) & $43.5 \%$ & $35.0 \%$ & & \\
\hline Medical care during pregnancy $(\%)$ & $16.1 \%$ & $15.0 \%$ & & \\
\hline Time when pregnancy detected $(\%)$ & $12.9 \%$ & $7.5 \%$ & & \\
\hline Medical complications during pregnancy $(\%)$ & $8.1 \%$ & $7.5 \%$ & & \\
\hline Personal info of biol. Mother (sum) (Mean, SD) & $2.81(2.86)$ & $2.43(2.07)$ & $t(100)=0.728$ & .468 \\
\hline Personal info of biol. Mother (any) (\%) & $72.6 \%$ & $77.5 \%$ & $\chi^{2}(1)=0.310$ & .578 \\
\hline Age $(\%)$ & $56.5 \%$ & $50.0 \%$ & & \\
\hline Country of origin $(\%)$ & $41.9 \%$ & $40.0 \%$ & & \\
\hline Physical Appearance (\%) & $37.1 \%$ & $32.5 \%$ & & \\
\hline Citizenship (\%) & $32.3 \%$ & $30.0 \%$ & & \\
\hline Education / Occupation (\%) & $29.0 \%$ & $32.5 \%$ & & \\
\hline Marital status (\%) & $27.4 \%$ & $20.0 \%$ & & \\
\hline Personal preferences $(\%)$ & $17.7 \%$ & $12.5 \%$ & & \\
\hline Medical information (\%) & $16.1 \%$ & $10.0 \%$ & & \\
\hline Personal talents $(\%)$ & $8.1 \%$ & $5.0 \%$ & & \\
\hline Religious belief $(\%)$ & $6.5 \%$ & $7.5 \%$ & & \\
\hline Genetic diseases $(\%)$ & $4.8 \%$ & $2.5 \%$ & & \\
\hline Genetic link between biol. Parents (\%) & $3.2 \%$ & $0.0 \%$ & & \\
\hline Personal info of biol. Father (sum) (mean, SD) & $0.47(1.14)$ & $0.50(1.09)$ & $t(100)=0.142$ & .887 \\
\hline Personal info of biol. Father (any) (\%) & $17.7 \%$ & $22.5 \%$ & $\chi^{2}(1)=0.349$ & .555 \\
\hline Country of origin $(\%)$ & $11.3 \%$ & $12.5 \%$ & & \\
\hline Marital status (\%) & $8.1 \%$ & $10.0 \%$ & & \\
\hline Age $(\%)$ & $8.1 \%$ & $5.0 \%$ & & \\
\hline Education / Occupation (\%) & $8.1 \%$ & $5.0 \%$ & & \\
\hline Physical Appearance (\%) & $4.8 \%$ & $5.0 \%$ & & \\
\hline Citizenship (\%) & $3.2 \%$ & $5.0 \%$ & & \\
\hline Medical information (\%) & $1.6 \%$ & $2.5 \%$ & & \\
\hline Personal talents $(\%)$ & $1.6 \%$ & $2.5 \%$ & & \\
\hline Genetic link between biol. Parents (\%) & $0.0 \%$ & $2.5 \%$ & & \\
\hline Religious belief (\%) & $0.0 \%$ & $0.0 \%$ & & \\
\hline Genetic diseases $(\%)$ & $0.0 \%$ & $0.0 \%$ & & \\
\hline Personal preferences $(\%)$ & $0.0 \%$ & $0.0 \%$ & & \\
\hline Memorials of biol. Mother (sum) (Mean, SD) & $0.95(0.82)$ & $0.90(0.93)$ & $t(100)=0.295$ & .769 \\
\hline Memorials of biol. Mother (any) (\%) & $69.4 \%$ & $60.0 \%$ & $\chi^{2}(1)=0.944$ & .331 \\
\hline Letter $(\%)$ & $35.5 \%$ & $35.0 \%$ & & \\
\hline Photos $(\%)$ & $9.7 \%$ & $10.0 \%$ & & \\
\hline Statement reasons for leaving child behind (\%) & $50.0 \%$ & $45.0 \%$ & & \\
\hline Memorials of biol. Father (sum) (Mean, SD) & $0.02(0.13)$ & $0.05(0.22)$ & $t(100)=0.983$ & .328 \\
\hline
\end{tabular}


Table 2 (continued)

\begin{tabular}{lllr}
\hline & $\begin{array}{l}\text { Adoptive mothers } \\
(\mathrm{N}=62)\end{array}$ & $\begin{array}{l}\text { Adoptive fathers } \\
(\mathrm{N}=40)\end{array}$ & \begin{tabular}{c} 
Group difference \\
\cline { 2 - 4 }
\end{tabular} \\
\hline Memorials of biol. Father (any) (\%) & $1.6 \%$ & $5.0 \%$ & $\chi^{2}(1)=0.977$ \\
Statement reasons for leaving child behind (\%) & $1.6 \%$ & $2.5 \%$ & .323 \\
Letter $(\%)$ & $0.0 \%$ & $2.5 \%$ & \\
Photos $(\%)$ & $0.0 \%$ & $0.0 \%$ & \\
\hline
\end{tabular}

Biol., Biological

about $50 \%$ of women left information on why she was not able to raise the child (Bonnet, 1999). This emphasizes the need to rework the processes surrounding anonymous delivery. Medical staff should strive to gather as much medical information as possible whilst maintaining the birth mother's anonymity.

\section{Differences between Adoptive Mothers and Fathers}

Only few differences emerged between adoptive parents in the present study: Adoptive mothers reported to be more anxious than adoptive fathers. Also, mothers rated their ability to communicate stress as better, and indicated the couple's capacity to conjointly cope with stress as higher than did adoptive fathers.

Higher levels of anxiety in adoptive mothers correspond with the consistently higher prevalence of anxiety disorders among women (McLean et al., 2011). However, comparisons of current and past results are complicated by the fact that only few studies focus on anxiety in adoptive parents; and those that do so, fail to analyze adoptive mothers and fathers separately (Anthony et al., 2019). One of the few existing studies (Mott et al., 2011) examined adoptive mothers and found their anxiety levels to be lower than those of birth mothers. This may be due to the fact that adoptive mothers - contrary to birth mothers - do not go through hormonal changes and the experience of delivery. Instead, however, they are confronted with other stressors such as infertility (Daniluk \& Hurtig-Mitchell, 2003), the application for adoption, undergoing agency evaluations, as well as the fear that their application may be contested, or that the birth parents may reclaim the child (Anthony et al., 2019). As such, the role of anxiety in adoptive mothers - particularly in comparison to adoptive fathers warrants further investigation.

Interestingly, while adoptive mothers reported more anxiety in our study, they also rated their ability to communicate stress and their common dyadic coping as higher than did adoptive fathers. Hence, women raising an anonymously born child reported to communicate their stress more often to their partner and to more frequently ask for their according support than did adoptive fathers. Additionally, they assessed their conjoint coping strategies as more favorable than did adoptive fathers, i.e., stating more often that they - as a couple - engaged in mutual problem solving and emotion sharing.

Given that for women, in particular, both their own dyadic coping and that of their partner has been found to impact marital quality over time (Bodenmann et al., 2006), high coping scores for both the relationship dimension and themselves may be regarded a positive sign. Also, our findings support prior research on both non-adoptive couples (Bodenmann et al., 2006) and adoptive couples (Canzi et al., 2019a), which shows that the partner's coping is more important for women than vice versa. The current study for the first time not only investigated dyadic coping in parents who already raised an adopted child (in contrast to Canzi et al., 2019a, who examined prospective adoptive parents), but also made an effort to account for gender differences (Hock \& Mooradian, 2012 only assessed adoptive mothers). As such, it sheds more light on a hitherto under-investigated subject.

\section{Predictors of Dyadic Coping}

In the current study, adoptees' psychopathology and age, as well as adoptive parents' age and biographical knowledge all emerged as significant predictors of adoptive parents' dyadic coping. Additionally, parents' mental health barely failed to reach significance, indicating a trend that worse parental mental health is associated with worse dyadic coping. Past data show an impact of parental psychopathologies on relationship quality and stress coping (Viana \& Welsh, 2010), notably in the context of raising an adoptee (Goldberg \& Smith, 2014). Yet, further research is needed to confirm this tendency.

The strongest predictor of parental dyadic coping was child psychopathology. The more externalizing and internalizing problems adoptive parents identified in their adoptive child, the less positive dyadic coping abilities they reported for themselves. It is known that health problems in children affect parents' stress levels and parental coping - not only in biological, but also in adoptive parents (Canzi et al., 2019c; Smith et al., 2018; Viana \& Welsh, 2010). While this seems to be 
Table 3 Difference between adoptive mothers and adoptive fathers regarding mental health, dyadic coping and attachment styles

\begin{tabular}{|c|c|c|c|c|c|c|c|c|}
\hline \multirow[t]{2}{*}{ Outcome variable } & \multicolumn{2}{|c|}{ Adoptive mothers } & \multicolumn{2}{|c|}{ Adoptive fathers } & \multicolumn{2}{|l|}{ Test statistic } & \multicolumn{2}{|l|}{ Effect size } \\
\hline & Mean & SD & Mean & SD & $t(\mathrm{df})$ & $p$ & Cohen's $d$ & $95 \% \mathrm{CI}$ \\
\hline BSI - Total score & 7.20 & 7.30 & 6.05 & 7.26 & $0.767(97)$ & .445 & 0.16 & {$[-0.25 ; 0.56]$} \\
\hline Somatization & 0.87 & 1.21 & 0.51 & 1.00 & $1.517(97)$ & .132 & 0.31 & {$[-0.09 ; 0.72]$} \\
\hline Obsessive-Compulsive & 1.32 & 1.80 & 1.03 & 1.55 & $0.830(97)$ & .409 & 0.17 & {$[-0.23 ; 0.57]$} \\
\hline Interpersonal Sensitivity & 0.68 & 0.95 & 0.51 & 0.89 & $0.898(97)$ & .372 & 0.19 & {$[-0.22 ; 0.59]$} \\
\hline Depression & 0.42 & 0.79 & 0.44 & 1.07 & $-0.103(97)$ & .918 & -0.02 & {$[-0.42 ; 0.38]$} \\
\hline Anxiety & 0.87 & 1.16 & 0.39 & 0.71 & $2.330(97)$ & .022 & 0.48 & {$[0.07 ; 0.89]$} \\
\hline Hostility & 1.133 & 1.37 & 1.00 & 1.15 & $.503(97)$ & .616 & 0.10 & {$[-0.30 ; 0.51]$} \\
\hline Phobic Anxiety & 0.22 & 0.61 & 0.41 & 0.72 & $-1.437(97)$ & .154 & -0.30 & {$[-0.70 ; 011]$} \\
\hline Paranoid Ideation & 0.90 & 1.40 & 0.77 & 1.27 & $0.472(97)$ & .638 & 0.10 & {$[-0.31 ; 0.50]$} \\
\hline Psychoticism & 0.13 & 0.39 & 0.33 & 1.06 & $-1.333(97)$ & .186 & -0.27 & {$[-0.68 ; 0.13]$} \\
\hline Total DCI Score & 128.51 & 21.55 & 122.90 & 18.69 & $1.328(96)$ & .187 & 0.27 & {$[-0.13 ; 0.68]$} \\
\hline Stress communicated by oneself & 14.92 & 2.593 & 12.85 & 3.70 & $3.273(97)$ & $<.001$ & 0.67 & {$[0.26 ; 1.09]$} \\
\hline Supportive dyadic coping by oneself & 19.27 & 3.463 & 17.97 & 3.65 & $1.775(96)$ & .079 & 0.37 & {$[-0.04 ; 0.77]$} \\
\hline Delegated dyadic coping by oneself & 7.63 & 1.790 & 7.87 & 1.32 & $-0.732(96)$ & .466 & -0.15 & {$[-0.56 ; 0.25]$} \\
\hline Negative dyadic coping by oneself & 17.29 & 2.901 & 16.51 & 2.99 & $1.279(96)$ & .204 & 0.26 & {$[-0.14 ; 0.67]$} \\
\hline Stress communication of the partner & 13.03 & 3.667 & 14.10 & 2.89 & $-1.531(96)$ & .129 & -0.32 & {$[-0.72 ; 0.09]$} \\
\hline Supportive dyadic coping of the partner & 18.90 & 4.784 & 18.05 & 3.98 & $0.916(96)$ & .362 & 0.19 & {$[-0.22 ; 0.59]$} \\
\hline Delegated dyadic coping of the partner & 7.48 & 1.951 & 6.85 & 2.20 & $1.485(96)$ & .141 & 0.31 & {$[-0.10 ; 0.71]$} \\
\hline Negative dyadic coping by the partner & 16.88 & 3.691 & 16.97 & 2.69 & $-0.135(96)$ & .893 & -0.03 & {$[-0.43 ; 0.38]$} \\
\hline Common dyadic coping & 17.00 & 3.849 & 15.26 & 3.75 & $2.225(97)$ & .028 & 0.46 & {$[0.05 ; 0.87]$} \\
\hline Evaluation of dyadic coping & 7.97 & 1.983 & 7.77 & 1.60 & $0.521(97)$ & .603 & 0.11 & {$[-0.30 ; 0.51]$} \\
\hline Total VASQ score & 48.90 & 9.43 & 48.13 & 8.33 & $0.414(96)$ & .680 & 0.09 & {$[-0.32 ; 0.49]$} \\
\hline Insecurity & 23.07 & 5.49 & 23.36 & 5.72 & $-0.253(96)$ & .801 & -0.05 & {$[-0.46 ; 0.35]$} \\
\hline Proximity Seeking & 25.83 & 5.70 & 24.77 & 5.01 & $0.945(96)$ & .347 & 0.20 & {$[-0.21 ; 0.60]$} \\
\hline
\end{tabular}

Statistically significant differences $(p<.05)$ are printed in bold

BSI, Brief Symptom Inventory; DCI, Dyadic Coping Inventory; VASQ, Vulnerable Attachment Style Questionnaire

true also for our sample, it must be noted that, in general, children's psychopathology scores were largely rated as clinically inconspicuous in our study (mean T-score around 50). Yet, a restriction is that the effects between parental dyadic coping and child psychopathology are likely bidirectional, with recent findings suggesting an influence of negative dyadic coping on internalizing and externalizing symptoms in children (Zemp et al., 2016). Longitudinal designs are needed to take this interdependence of child and parental well-being into account, and adoption services are called upon to implement interventions supporting not only adoptive parents but the whole family system (Hock \& Mooradian, 2012).

In addition to child psychopathology, older parents' age and younger adoptees' age were both associated with better dyadic coping. Consistent with prior research on non-adoptive couples (Acquati \& Kayser, 2019), older adoptive parents reported more successful dyadic coping than younger ones in our study. In general, coping abilities tend to increase with age, and vulnerability to distress is documented to decrease with age (e.g. Revenson, 2003). Additional determinants of a couple's dyadic coping are contextual factors like finances and lifestyle (Acquati \& Kayser, 2019). Adoptive parents represent a particular selection of couples, as they a priori tend to be older, financially secure (Calvo et al., 2015; Smith et al., 2018) and well-educated. Also, they have often been in a relationship longer and are screened beforehand regarding their fitness to become parents (Calvo et al., 2015; Lee et al., 2018; Roberson, 2006). Thus, they are likely to have a lengthy period of transitioning into parenthood. All of the above may act as protective factors with regard to the couple's relationship, as well as their ability to cope with parental demands.

With regard to the adoptive child's age as a predictor of dyadic coping, there are to our knowledge no definite accounts in the extant literature. Both are assumed to vary over time (e.g., Neece et al., 2012), as development-specific challenges such as the need to find out more about their biographies (see SkinnerDrawz et al., 2011; Wrobel \& Dillon, 2009) are likely to exert an age-dependent influence on parental coping. 
Table 4 Hierarchical linear regression analysis predicting parental dyadic coping

\begin{tabular}{|c|c|c|c|c|}
\hline Model summary & $\mathrm{R}$ & $\mathrm{R}^{2}$ & $\Delta \mathrm{R}^{2}$ & $\Delta \mathrm{p}$ \\
\hline Model $1^{\mathrm{a}}$ & .241 & .058 & .058 & .396 \\
\hline Model $2^{\mathrm{b}}$ & .345 & .119 & .061 & .018 \\
\hline Model $3^{\mathrm{c}}$ & .543 & .295 & .177 & $<.001$ \\
\hline Model $4^{\mathrm{d}}$ & .588 & .346 & .051 & .048 \\
\hline Regression coefficients (model 3) & $\mathrm{b}(\mathrm{SE})$ & Beta & $t$ & $p$ \\
\hline Intercept & $193.157(22.50)$ & & 8.583 & $<.001$ \\
\hline Gender (parent) $)^{\mathrm{e}}$ & $5.851(3.96)$ & .134 & 1.478 & .143 \\
\hline Age (parent) & $-1.127(0.42)$ & -.319 & -2.685 & .009 \\
\hline Gender (child) ${ }^{\mathrm{e}}$ & $-1.404(3.85)$ & -.033 & -0.365 & .716 \\
\hline Age (child) & $2.702(1.23)$ & .457 & 2.205 & .030 \\
\hline Time since adoption & $-0.983(1.23)$ & -.168 & -0.798 & .427 \\
\hline Number of known background factors & $1.143(0.45)$ & .251 & 2.531 & .013 \\
\hline Adoptive child's psychopathology & $-0.592(0.18)$ & -.334 & -3.228 & .002 \\
\hline Parental psychopathology & $-0.603(0.33)$ & -.200 & -1.855 & .067 \\
\hline Parental attachment styles & $-0.216(0.23)$ & -.093 & -0.931 & .355 \\
\hline
\end{tabular}

Statistically significant results $(p<.05)$ are printed in bold

${ }^{\text {a }}$ Predictors included: Gender, age (adoptive parents and children), time since adoption;

${ }^{\mathrm{b}}$ Predictors included: Gender, age (adoptive parents and children), time since adoption, number of known background factors;

${ }^{\mathrm{c}}$ Predictors included: Gender, age (adoptive parents and children), time since adoption, number of known background factors, child's psychopathology (CBCL total score);

${ }^{\mathrm{d}}$ Predictors included: Gender, age (adoptive parents and children), time since adoption, number of known background factors, child's psychopathology (CBCL total score), parental psychopathology (BSI total score), Parental attachment style (VASQ total score)

${ }^{\mathrm{e}} 1=$ male, 2 = female

Finally, biographical knowledge emerged as a predictor of dyadic coping. In other words, more biographical knowledge - represented by the higher number of mentioned facts - was significantly associated with better dyadic coping in adoptive couples. As mentioned above, adoptive parents have a vested interest in learning more about their child's past - to satisfy their own curiosity (Shaw, 2011) and to support their child in developing an adoptive identity (Farr et al., 2018). Not knowing about the adoptee's history may constitute a stressor (see Bird et al., 2002), and the ability to fill these gaps in knowledge may in turn reduce stress in adoptive couples. Accordingly, openness in adoption has been shown to positively impact family communication and stress (Grotevant et al., 2019). This study - to our knowledge - is the first to show that this is also true for adoptive parents' dyadic coping.

\section{Limitations and Conclusion}

A strength of the present study lies in the fact that it considers a previously understudied sample, i.e., adoptive mothers and adoptive fathers of an anonymously born child. It focuses on key variables which are known to shape parental ability to cope with stress, and it accounts for possible mother-father- differences. Apart from these assets, however, there are also several limitations to this study.

Most importantly, a cross-sectional design is not fit to capture changes over time. Stressors are expected to vary over time and hence, longitudinal studies are needed to better reflect the processual nature of adoptive parenting. Similarly, causal relationships cannot be determined based on a single assessment. Also, claims about influences of pre-existing mental health issues or pre-adoption attachment styles are precluded with the current design. In a similar vein, this study relied on independent samples. While these are valid for assessing differences between mothers and fathers, dyadic analyses would provide more insight into couple dynamics, particularly with regard to dyadic coping (Bodenmann et al., 2006). Also, they would allow for a more comprehensive analysis of parental accounts of child psychopathology. While in our study reports did not differ, past research (see meta-analyses of Achenbach et al., 1987, and Duhig et al., 2000) unanimously points at only moderate agreement between mothers and fathers. Additionally, self-report measures pose several limitations: Using the same source for reporting (e.g. on child psychopathology and one's own mental health) tends to inflate associations (Hails et al., 2019), and socially 
desirable responses, poor self-reflection and misunderstanding of items may limit generalizability. Correspondingly, mailing questionnaires or using online tools limits the ability to determine who participated. Reverting to different sources and behavioral measures could counteract this problem in future research. Also, with a mean age of 6 years, the current sample of adoptees was quite young. This fact precludes conclusions about older adoptees (e.g. adolescents or those at the verge of transition into adulthood) who may face other challenges than younger adoptees. Finally, adding a parallelized control group of biological parents - instead of comparing scores to the norm population - would undoubtedly strengthen the study's validity (see Caballo et al., 2001).

Despite these limitations, the current results are both valuable in terms of guiding future research endeavors, and for improving social service policies tailored to the particularities of safe surrender programs like anonymous birth. Given the importance of biographical knowledge for both, adoptive children and adoptive parents, policies should include solutions for how to reach women who wish to deliver anonymously. Above all, knowledge on the possibility to anonymously attend pre-natal care and awareness of the significance of leaving biographical data or personal memoires (letter, photographs) should be promoted. Similarly, medical staff should be trained in how to sensibly motivate anonymously delivering women to leave personal information whilst giving them the security of remaining anonymous. Furthermore, this underlines the need to strive for replacing baby hatches by anonymous birth practices, as the latter offer a greater chance of collecting biographical information. This is also crucial given that there are many countries which only have the option of placing a newborn in a baby hatch and do not promote anonymous birth (see http://anonymegeburt.at/en/anogeb-eur-map/).

To be able to develop and provide approaches which are tailored to the needs of affected women, research should strive to include these women in corresponding studies. At this point, there is only very limited data on anonymously delivering women and there is a definite lack of knowledge on their reasons for choosing anonymous birth and safe relinquishment (Bonnet, 1993).

The present study paved the ground for further research on the specific roles and needs of adoptive mothers and fathers. Particularly, the increased level of anxiety in adoptive mothers found in the current sample warrants further study with regard to its causes. Specific predictors of parenting fears in the context of adoption (e.g. the fear that the child may be reclaimed) should be evaluated separately to determine their impact. Also, these fears should be addressed by adoption services and prospective adoptive parents should be educated about the unique challenges linked to anonymous birth. Finally, the reciprocity regarding parents' and children's well-being warrants interventions which target the whole family system.
Funding Open access funding provided by Medical University of Vienna.

\section{Declarations}

Conflict of Interest On behalf of all authors, the corresponding author states that there is no conflict of interest.

Open Access This article is licensed under a Creative Commons Attribution 4.0 International License, which permits use, sharing, adaptation, distribution and reproduction in any medium or format, as long as you give appropriate credit to the original author(s) and the source, provide a link to the Creative Commons licence, and indicate if changes were made. The images or other third party material in this article are included in the article's Creative Commons licence, unless indicated otherwise in a credit line to the material. If material is not included in the article's Creative Commons licence and your intended use is not permitted by statutory regulation or exceeds the permitted use, you will need to obtain permission directly from the copyright holder. To view a copy of this licence, visit http://creativecommons.org/licenses/by/4.0/.

\section{References}

Achenbach, T. M. (1991). Manual for the child behavior checklist/4-18 and 1991 profile. University of Vermont, Department of Psychiatry.

Achenbach, T. M., McConaughy, S. H., \& Howell, C. T. (1987). Child/ adolescent behavioral and emotional problems: Implications of cross-informant correlations for situational specificity. Psychological Bulletin, 101(2), 213-232. https://doi.org/10.1037/ 0033-2909.101.2.213.

Achenbach, T. M., \& Rescorla, L. A. (2000). Manual for the ASEBA Preschool Forms \& Profiles. University of Vermont, Research Center for Children, Youth, \& Families.

Acquati, C., \& Kayser, K. (2019). Dyadic coping across the lifespan: A comparison between younger and middle-aged couples with breast cancer. Frontiers in Psychology, 10, 404. https://doi.org/10.3389/ fpsyg.2019.00404.

Alves, S., Fonseca, A., Canavarro, M. C., \& Pereira, M. (2020). Does dyadic coping predict couples' postpartum psychosocial adjustment? A dyadic longitudinal study. Frontiers in Psychology, 11, 2401. https://doi.org/10.3389/fpsyg.2020.561091.

Anthony, R. E., Paine, A. L., \& Shelton, K. H. (2019). Depression and anxiety symptoms of British adoptive parents: A prospective fourwave longitudinal study. International Journal of Environmental Research and Public Health, 16(24), 5153. https://doi.org/10. 3390/ijerph16245153.

Belsky, J. (1984). The determinants of parenting: A process model. Child Development, 55, 83-96. https://doi.org/10.2307/1129836.

Berg, C. A., \& Upchurch, R. (2007). A developmental-contextual model of couples coping with chronic illness across the adult life span. Psychological Bulletin, 133(6), 920-954.

Bifulco, A., Mahon, J., Kwon, J. H., Moran, P. M., \& Jacobs, C. (2003). The vulnerable attachment style questionnaire (VASQ): An interview-based measure of attachment styles that predict depressive disorder. Psychological Medicine, 33(6), 1099-1110. https://doi. org/10.1037/0033-2909.133.6.920.

Bird, G. W., Peterson, R., \& Miller, S. H. (2002). Factors associated with distress among support-seeking adoptive parents. Family Relations, 51(3), 215-220. https://doi.org/10.1111/j.1741-3729.2002.00215.x.

Bodenmann, G. (1995). A systemic-transactional conceptualization of stress and coping in couples. Swiss Journal of Psychology, 54, 34 49. 
Bodenmann, G. (2008). Dyadisches coping inventar: Testmanual. [dyadic coping inventory]. Huber.

Bodenmann, G., Arista, L. J., Walsh, K. J., \& Randall, A. K. (2018). Dyadic coping inventory. In Encyclopedia of couple and family therapy (pp. 1-5). Springer, Cham.

Bodenmann, G., Pihet, S., \& Kayser, K. (2006). The relationship between dyadic coping and marital quality: A 2-year longitudinal study. Journal of Family Psychology, 20(3), 485-493. https://doi.org/10. 1037/0893-3200.20.3.485.

Bonnet, C. (1993). Adoption at birth: Prevention against abandonment or neonaticide. Child Abuse Negl, 17(4), 501-513. https://doi.org/10. 1016/0145-2134(93)90025-z.

Bonnet, C. (1999). Maternités impossibles et accouchement sous X. La Lettre du gynécologue, 238, 11-13.

Bowlby, J. (1973). Attachment and loss: Volume II: Separation, anxiety and anger. In Attachment and loss: Volume II: Separation, anxiety and anger (pp. 1-429). The Hogarth press and the institute of psycho-analysis.

Caballo, R., Lansford, J. E., Abbey, A., \& Stewart, A. J. (2001). Theoretical perspectives on adoptive families' well-being: Which comparison groups are most appropriate? Marriage \& Family Review, 33(4), 85-105. https://doi.org/10.1300/J002v33n04_07.

Caltabiano, M. L., \& Thorpe, R. (2007). Attachment style of foster carers and caregiving role performance. Child Care in Practice, 13(2), 137-148. https://doi.org/10.1080/13575270701201201.

Calvo, V., Palmieri, A., Codamo, A., Scampoli, M. R., \& Bianco, F. (2015). Perceptions of parental bonding, adult attachment, and marital adjustment in prospective adoptive parents. An empirical study in the pre-adoptive period. Sexual and Relationship Therapy, 30(4), 419-432. https://doi.org/10.1080/14681994.2014.1001355.

Canzi, E., Donato, S., Ferrari, L., Parise, M., Pagani, A. F., Lopez, G., Rosnati, R., \& Ranieri, S. (2019a). "What makes us strong?": Dyadic coping in Italian prospective adoptive couples. Frontiers in Psychology, 10, 399. https://doi.org/10.3389/fpsyg.2019.00399.

Canzi, E., Molgora, S., Fenaroli, V., Rosnati, R., Saita, E., \& Ranieri, S. (2019b). "Your stress is my stress": A dyadic study on adoptive and biological first-time parents. Couple and Family Psychology: Research and Practice, 8(2), 197-207. https://doi.org/10.1037/ cfp0000127.

Canzi, E., Ranieri, S., Barni, D., \& Rosnati, R. (2019c). Predictors of parenting stress during early adoptive parenthood. Current Psychology, 38(3), 811-820. https://doi.org/10.1007/s12144-0179657-x.

Daniluk, J. C., \& Hurtig-Mitchell, J. (2003). Themes of hope and healing: Infertile couples' experiences of adoption. Journal of Counseling and Development, 81(4), 389-399. https://doi.org/10.1002/j.15566678.2003.tb00265.x.

Duhig, A. M., Renk, K., Epstein, M. K., \& Phares, V. (2000). Interparental agreement on internalizing, externalizing, and Total problems: A meta-analysis. Clinical Psychology: Science and Practice, 7, 435-453. https://doi.org/10.1093/clipsy.7.4.435.

Falconier, M. K., Jackson, J. B., Hilpert, P., \& Bodenmann, G. (2015). Dyadic coping and relationship satisfaction: A meta-analysis. Clinical Psychology Review, 42, 28-46. https://doi.org/10.1016/j. cpr.2015.07.002.

Farr, R. H., Ravvina, Y., \& Grotevant, H. D. (2018). Birth family contact experiences among lesbian, gay, and heterosexual adoptive parents with school-age children. Family Relations, 67(1), 132-146. https:// doi.org/10.1111/fare.12295.

Felnhofer, A., Bussek, T., Goreis, A., Kafka, J. X., König, D., Klier, C., Zesch, H., \& Kothgassner, O. D. (2020). Mothers' and fathers' perspectives on the causes of their Child's disorder. Journal of Pediatric Psychology, 45(7), 803-811. https://doi.org/10.1093/ jpepsy/jsaa056.

Felnhofer, A., Goreis, A., Bussek, T., Kafka, J. X., König, D., Klier, C., Zesch, H., \& Kothgassner, O. D. (2019). Evaluating parents' and
Children's assessments of competence, health related quality of life and illness perception. Journal of Child and Family Studies, 28(10), 2690-2699. https://doi.org/10.1007/s10826-019-01449-x.

Ferrari, L., Ranieri, S., Barni, D., \& Rosnati, R. (2015). Parent-child relationship and adoptees' psychological well-being in adolescence and emerging adulthood: Disentangling maternal and paternal contribution. Family Science, 6(1), 77-86. https://doi.org/10.1080/ 19424620.2015.1081005.

Franke, G. H. (2000). Brief symptom inventory von Derogatis (BSI). Beltz Test.

Galliez, S., Klier, C., Felnhofer, A., \& Kernreiter, J. (2019). Die Anonyme Geburt in Österreich: Aktuelle Durchführungspraxis und Optimierungspotential aus Anlass der Volljährigkeit der vom Erlass vom 27. Juli 2001 über Babynest und anonyme Geburt JMZ 4.600/42-I.1/2001betroffenen Personen, http:// anonymegeburt.at/wp-content/uploads/2020/06/REPORT ANOGEB_\%C3\%96_Version1.pdf Accessed 15 October 2020.

Goldberg, A. E., \& Smith, J. Z. (2014). Predictors of parenting stress in lesbian, gay, and heterosexual adoptive parents during early parenthood. Journal of Family Psychology, 28(2), 125-137. https://doi. org/10.1037/a0036007.

Grotevant, H. D., Wrobel, G. M., Fiorenzo, L., Lo, A. Y., \& McRoy, R. G. (2019). Trajectories of birth family contact in domestic adoptions. Journal of Family Psychology, 33(1), 54-63. https://doi.org/ 10.1037/fam0000449.

Grylli, C., Brockington, I., Fiala, C., Huscsava, M., Waldhoer, T., \& Klier, C. M. (2016). Anonymous birth law saves babiesOptimization, sustainability and public awareness. Archives of Women's Mental Health, 19(2), 291-297. https://doi.org/10.1007/ s00737-015-0567-3.

Hails, K. A., Shaw, D. S., Leve, L. D., Ganiban, J. M., Reiss, D., Natsuaki, M. N., \& Neiderhiser, J. M. (2019). Interaction between adoptive mothers' and fathers' depressive symptoms in risk for children's emerging problem behavior. Social Development, 28(3), 725-742. https://doi.org/10.1111/sode.12352.

Henze-Pedersen, S. (2019). Known and unknown identities: Openness and identity as experienced by adult adoptees. Adoption Quarterly, 22(2), 135-156. https://doi.org/10.1080/10926755.2019.1625834.

Hilpert, P., Randall, A. K., Sorokowski, P., Atkins, D. C., Sorokowska, A., Ahmadi, K., et al. (2016). The associations of dyadic coping and relationship satisfaction vary between and within nations: A 35nation study. Frontiers in Psychology, 7, 1106. https://doi.org/10. 3389/fpsyg.2016.01106.

Hock, R. M., \& Mooradian, J. K. (2012). Co-parenting quality among adoptive mothers: Contributions of socioeconomic status, child demands and adult relationship characteristics. Child \& Family Social Work, 17(1), 85-95. https://doi.org/10.1111/j.1365-2206.2011. 00775.x.

Judge, S. (2003). Determinants of parental stress in families adopting children from Eastern Europe. Family Relations: An Interdisciplinary Journal of Applied Family Studies, 52, 241-248. https://doi.org/10.1111/j.1741-3729.2003.00241.x.

Kaniuk, J., Steele, M., \& Hodges, J. (2004). Report on a longitudinal research project, exploring the development of attachments between older, hard-to-place children and their adopters over the first two years of placement. Adoption \& Fostering, 28(2), 61-67. https:// doi.org/10.1177/030857590402800208.

Lazarus, R. S., \& Folkman, S. (1984). Stress, appraisal, and coping. Springer.

Lee, B. R., Kobulsky, J. M., Brodzinsky, D., \& Barth, R. P. (2018). Parent perspectives on adoption preparation: Findings from the modern adoptive families project. Children and Youth Services Review, 85, 63-71. https://doi.org/10.1016/j.childyouth.2017.12. 007.

McLean, C. P., Asnaani, A., Litz, B. T., \& Hofmann, S. G. (2011). Gender differences in anxiety disorders: Prevalence, course of 
illness, comorbidity and burden of illness. Journal of Psychiatric Research, 45(8), 1027-1035. https://doi.org/10.1016/j.jpsychires. 2011.03.006.

Meuwly, N., Bodenmann, G., Germann, J., Bradbury, T. N., Ditzen, B., \& Heinrichs, M. (2012). Dyadic coping, insecure attachment, and cortisol stress recovery following experimentally induced stress. Journal of Family Psychology, 26(6), 937-947. https://doi.org/10. 1037/a0030356.

Mott, S. L., Schiller, C. E., Richards, J. G., O’Hara, M. W., \& Stuart, S. (2011). Depression and anxiety among postpartum and adoptive mothers. Archives of Women's Mental Health, 14(4), 335-343. https://doi.org/10.1007/s00737-011-0227-1.

Neece, C. L., Green, S. A., \& Baker, B. L. (2012). Parenting stress and child behavior problems: A transactional relationship across time. American Journal on Intellectual and Developmental Disabilities, 117(1), 48-66. https://doi.org/10.1352/1944-7558-117.1.48.

Orliss, M., Rogers, K., Rao, S., Deavenport-Saman, A., Imagawa, K. K., Roberts, S., Rafeedie, J., \& Hudson, S. M. (2019). Safely surrendered infants in Los Angeles County: A medically vulnerable population. Child: Care, Health and Development, 45(6), 861-866. https://doi.org/10.1111/cch.12711.

Phares, V., Lopez, E., Fields, S., Kamboukos, D., \& Duhig, A. M. (2005). Are fathers involved in pediatric psychology research and treatment? Journal of Pediatric Psychology, 30(8), 631-643. https:// doi.org/10.1093/jpepsy/jsi050.

Ponnet, K., Mortelmans, D., Wouters, E., Van Leeuwen, K., Bastaits, K., \& Pasteels, I. (2013). Parenting stress and marital relationship as determinants of mothers' and fathers' parenting. Personal Relationships, 20(2), 259-276. https://doi.org/10.1111/j.14756811.2012.01404.x.

Revenson, T. A. (2003). Scenes from a marriage: Examining support and marital coping with chronic illness, in Social psychological foundations of health and illness, eds. J. Suls and K. Wallston (Oxford: Blackwell Publishing), 530-559.

Roberson, K. C. (2006). Attachment and caregiving behavioral systems in intercountry adoption: A literature review. Children and Youth Services Review, 28(7), 727-740. https://doi.org/10.1016/j. childyouth.2005.07.008.

Rosnati, R., Ranieri, S., \& Barni, D. (2013). Family and social relationships and psychosocial well-being in Italian families with internationally adopted and non-adopted children. Adoption Quarterly, 16(1), 1-16. https://doi.org/10.1080/10926755.2012. 731030.

Shaw, J. (2011). (re) constructing the past: The role of memory and imagination among transnationally adopted children and their adoptive parents. PlatForum, 12, 93-93.

Skinner-Drawz, B. A., Wrobel, G. M., Grotevant, H. D., \& Von Korff, L. (2011). The role of adoption communicative openness in information seeking among adoptees from adolescence to emerging adulthood. Journal of Family Communication, 11(3), 181-197. https:// doi.org/10.1080/15267431003656587.

Smith, C., Cossette, L., Melançon, F., Beauvais-Dubois, C., Smolla, N., Gagnon-Oosterwaal, N., et al. (2018). Behavior problems in adolescence among international adoptees, pre-adoption adversity, and parenting stress. Journal of Applied Developmental Psychology, 57, 53-61. https://doi.org/10.1016/j.appdev.2018.04.005.

Viana, A. G., \& Welsh, J. A. (2010). Correlates and predictors of parenting stress among internationally adopting mothers: A longitudinal investigation. International Journal of Behavioral Development, 34(4), 363-373. https://doi.org/10.1177/0165025409339403.

Von Korff, L., \& Grotevant, H. D. (2011). Contact in adoption and adoptive identity formation: The mediating role of family conversation. Journal of Family Psychology, 25(3), 393-401. https://doi.org/10. 1037/a0023388.

Wrobel, G. M., \& Dillon, K. (2009). Adopted adolescents: Who and what are they curious about? In G. M. Wrobel \& E. Neil (Eds.), International advances in adoption research for practice (pp. 217-244). Wiley.

Wrobel, G. M., \& Grotevant, H. D. (2019). Minding the (information) gap: What do emerging adult adoptees want to know about their birth parents? Adoption Quarterly, 22(1), 29-52. https://doi.org/10. 1080/10926755.2018.1488332.

Zemp, M., Bodenmann, G., Backes, S., Sutter-Stickel, D., \& Revenson, T. A. (2016). The importance of parents' dyadic coping for children. Family Relations, 65(2), 275-286. https://doi.org/10.1111/fare. 12189.

Publisher's Note Springer Nature remains neutral with regard to jurisdictional claims in published maps and institutional affiliations. 